\section{Staying the Course}

\section{The Captain's Log Continues}

\author{
Irving Rootman, $\mathrm{PhD}^{1}$ \\ Deborah Gordon El-Bihbety, BA ${ }^{2}$
}

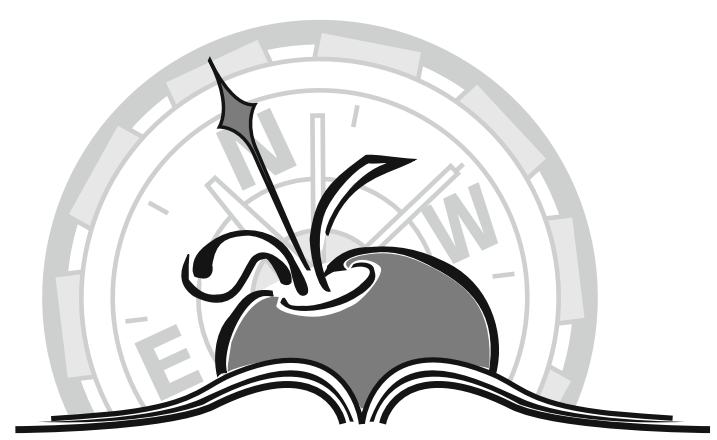

\section{ABSTRACT}

This paper introduces the reader to the context for the papers in this journal supplement by describing the background and task assigned to the authors, a short history of the development of the field of literacy and health in Canada, some recent developments and opportunities, some information on the nature and magnitude of the issue, and an overview of the supplement. The publication results from the Second Canadian Conference on Literacy and Health. Authors were asked to summarize what was learned at the conference, what we need to know, and what we need to do to move the field forward in relation to the themes of the conference. The four themes were: Building Best Practices in Literacy and Health; Focusing on Language and Culture; Building Knowledge in Literacy and Health; and Building Healthy Public Policy.

MeSH terms: Literacy; health; health literacy; conference proceedings

1. Centre for Community Health Promotion Research, University of Victoria, Victoria, BC 2. President and CEO, Research Canada, Ottawa, ON

Correspondence and reprint requests: Irving Rootman, Centre for Community Health Promotion Research, University of Victoria, Box 3060 STN CSC, Victoria, BC V8W 3R4, Tel: 250-472-4102, Fax: 250-472-4836, E-mail: irootman@uvic.ca
$\mathrm{T}$ he First Canadian Conference on Literacy and Health took place in

Ottawa in May 2000. A record of its proceedings, "The Captain's Log," was published. ${ }^{1}$ It faithfully recorded the proceedings and accomplishments of the conference. It also charted a course for literacy and health in Canada in the new millennium. This publication continues the entries into "The Captain's Log." It records the proceedings and accomplishments of the Second Canadian Conference on Literacy and Health, held in the same hotel in Ottawa, four and a half years later.

The goals of the first conference were to build and strengthen literacy and health partnerships and position literacy as a critical health issue. It addressed and formulated recommendations for each of the following five themes:

1. Making health services and health information easy to use for all Canadians

2. Looking for ways to improve the training of health practitioners

3. Learning more through research

4. Learning from learners

5. Building literacy and health partnerships.

In doing so, it helped the National Literacy and Health Program ("the program") map out its role. It also guided subsequent work in the field of literacy and health in Canada.

The second national conference was intended to build on the momentum created by the first. It meant to take stock of accomplishments in the field that followed. Specifically, its goals were to provide:

- A national forum to discuss what is being done to improve the health of Canadians with low literacy skills;

- An opportunity to: build new partnerships in literacy and health; share knowledge, skills, and practical tools; and identify future actions for all participants, in practice, policy, and research. The conference addressed four themes:

1. Building Best Practices in Literacy and Health

2. Focusing on Language and Culture

3. Building Knowledge in Literacy and Health

4. Building Healthy Public Policy.

The second conference was similar in some ways to the first conference. The themes were similar, it was organized in a 
comparable way, and there was attention given to learners through a "Learners' Gallery" and a "Learners' Forum," and involvement of learners in the program. But the second conference did have some unique features. These included online discussion groups and web forums as well as a workshop for graduate students before the conference. Graduate students were also involved as session chairs and recorders during the conference. The results of some of these activities, such as the graduate student workshop, are reported elsewhere. ${ }^{2}$ This contribution to the "Captain's Log" concentrates on reporting and analyzing what went on at the conference itself.

Specifically, the authors in this journal supplement were asked to reflect on the overarching goal of the conference of improving the health of Canadians with low literacy skills. They were also asked to:

- summarize the presentations, workshops, and discussions that took place at the conference in the four theme areas as well as on issues related to specific groups (Francophones, Aboriginal people, ethnocultural communities, and learners);

- identify gaps in knowledge, skills, or resources for the particular theme or group; and

- identify concrete steps to further the field of literacy and health in relation to the theme or group and to the goal of improving the health of Canadians with low literacy skills.

To set the stage for these papers, this article presents some background on: the development of the field of literacy and health in Canada; some recent developments and opportunities; the nature and magnitude of the issue; and this supplement.

\section{Where have we been?}

As a result of growing concerns in the early 1980s, fanned by media personality Peter Gzowski and other prominent Canadians, literacy was declared a national priority by Canada in 1986. The debate was fuelled by Southam Inc., who commissioned Toronto Star reporter, Peter Calamai, to investigate the problem through a national survey in 1987. Calamai's report, Broken Words: Why Five Million Canadians are Illiterate, ${ }^{3}$ shocked Canadians, who had not realized that almost $25 \%$ of Canadian adults could

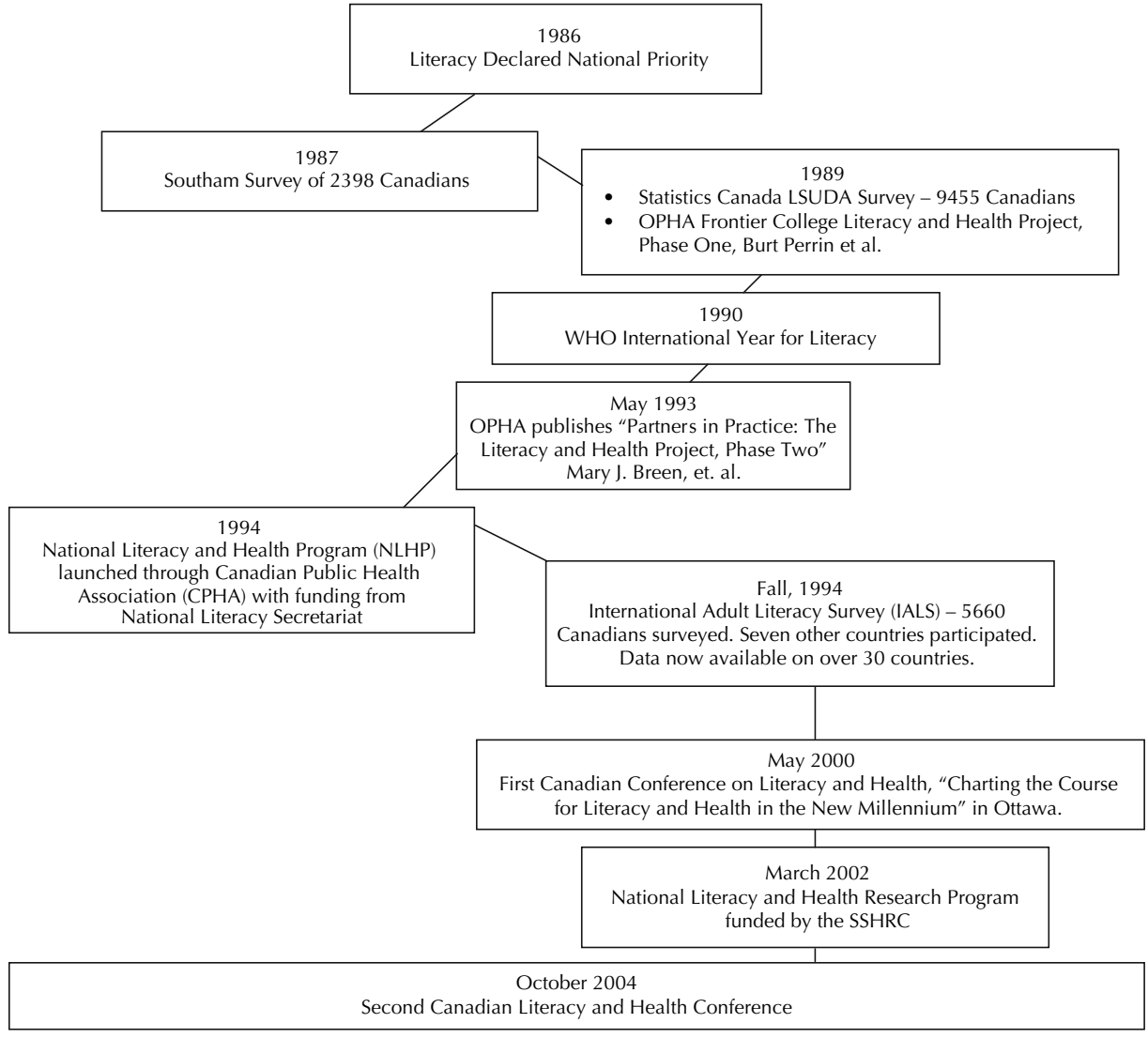

Figure 1. Milestones in Canadian Literacy and Health

not perform simple tasks such as reading road and building signs, or locating the expiry date on a driver's license or where to sign a registration form. Partly as a result of this growing concern, the National Literacy Secretariat (NLS) was established in 1988. International Literacy Year, celebrated in 1990, increased awareness of the problem and led to further actions in Canada and in other countries.

One such action was the development of the International Adult Literacy Survey (IALS). The survey was first carried out in Canada in 1994. It found about one fifth of the population at the lowest literacy levels, with "serious difficulty dealing with printed material." It also found that 25\% of the population were only able to deal with material that is simple and clearly laid out. ${ }^{4}$ This ground-breaking survey developed a reading and writing skills continuum along which a person's literacy level could be measured. This continuum was based on the approach that a person's reading and writing skills were relative to the different contexts and settings within which they needed to function, such as home, work, and community. In other words, literacy was a relative rather than an absolute skill.
Clearly, this new approach to measuring literacy was a breakthrough in our understanding of the impact of literacy on all aspects of a person's life, including their health. These findings were used to support the view of literacy as a major issue in the development of our labour force.

At the same time, there was growing concern in the health field about the possible contribution of low literacy to poor health. This concern was stimulated by a project on literacy and health conducted by the Ontario Public Health Association in partnership with Frontier College, the country's oldest literacy network. Their first report, Making the World Healthier and Safer for People Who Can't Read, was published in 1989. ${ }^{5}$ Their second, Partners in Practice, ${ }^{6}$ documented the increasing collaboration that their work had fostered among literacy workers, health service providers, and learners.

This was followed by the establishment of the the Canadian Public Health Association's (CPHA) National Literacy and Health Program with funding from the NLS in 1994. CPHA's ninth goal in its Mission Statement is to identify literacy as a major factor in achieving equitable access 


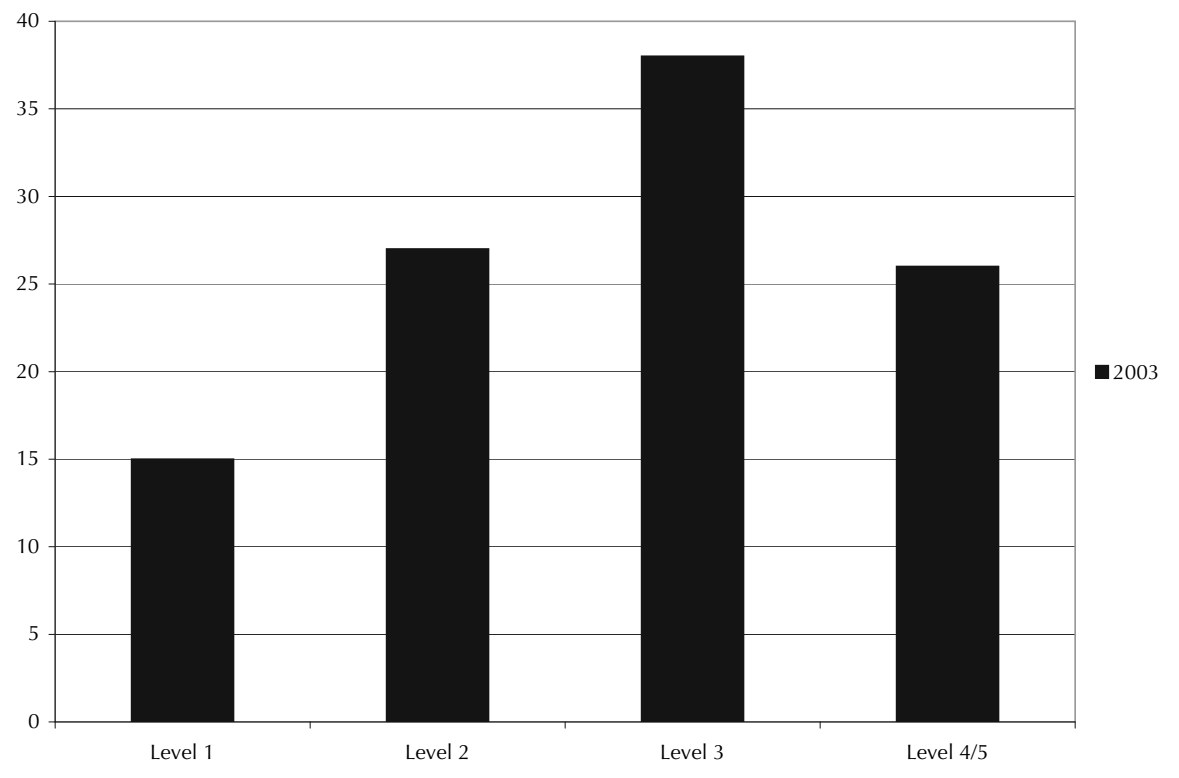

Figure 2. Scores on Prose Scale of Adult Literacy and Life Skills Survey ${ }^{9}$

to health services. The establishment of the program fulfilled the association's commitment to literacy as a key public health issue. It also led to a collaborative partnership with 26 national partners that has, over the years, strengthened the program's capacity to improve health services for consumers with literacy challenges.

The program has carried out several projects, organized conferences including the first and second Canadian conferences, and generated the publication and dissemination of countless plain language materials. In 1997, CPHA established its Plain Language Service. The service offers plain language revisions, clear design, and training workshops in plain language and clear verbal communication. The National Literacy and Health Program is considered a model for raising awareness, exploring issues, developing resource materials, and building partnerships in this field. Its work helped Canada to become an international leader in literacy and health.

\section{Where are we now?}

In 1999, Health Canada's second report on the health of Canadians, Towards a Healthy Future, ${ }^{7}$ profiled literacy as a social determinant of health for the first time. This landmark report demonstrated that while Canadians enjoy a high level of health, which continues to improve, this overall high standard is not shared equitably by all areas of society, including those Canadians with low literacy skills.
Since the first conference, several important developments have taken place. One was in 2002, when the Social Sciences and Humanities Research Council funded a project to develop a national program of research in literacy and health. Among other things, this project has: conducted an environmental scan and needs assessment; organized a national workshop to establish research priorities; obtained funding for several research projects; published numerous papers in professional journals; evaluated the National Literacy and Health Program; and organized a research institute and workshop for graduate students interested in the field. More details concerning the activities and products of this project can be found on the project website, which is part of the website of the National Literacy and Health Program. ${ }^{8}$ It is anticipated that this project will lead to a national program of research on literacy and health.

Another important development, since the first conference, was the establishment of a Committee on Health Literacy by the prestigious United States Institute of Medicine. The committee, which had two members from Canada, released its report in April 2004. ${ }^{4}$ The implications for Canada were discussed at CPHA's 2004 annual conference and at the Second Canadian Conference on Literacy and Health. In this context, it should be noted that "health literacy" is not the same as "literacy." Each term has different implica- tions for health. This was discussed at the second Canadian conference. It is explained further in other parts of the supplement.

Other developments since the first conference that have important implications for the field of literacy and health are: the establishment of the Canadian Institutes for Health Research, which have broadened the health research agenda to include topics such as literacy and health; the establishment of a Council on Learning by the federal government, which will have "Health and Learning" as one of its six nodes; and the establishment of the Canadian Public Health Agency, which will include literacy as one of its areas of interest. All of these developments bode well for the further strengthening of the field of literacy and health in Canada. They were discussed at the second Canadian conference, and are also reflected in the conference recommendations in the concluding article of this journal supplement.

\section{What kind of problem is literacy and health?}

As previously mentioned, according to the 1994 IALS, almost half of Canadian adults appeared to have some difficulties with reading prose in the official languages of Canada. Specifically, according to the report on the survey, $22 \%$ of Canadian adults fell into the lowest category (level 1) on the prose reading scale; another $26 \%$ fell into the second lowest category (level 2). This suggested that almost half (48\%) of Canadians did not have the literacy skills necessary to participate fully in the "knowledge economy."

The International Adult Literacy and Lifestyle Survey, released on May 11, 2005, builds on the IALS. It found that the average literacy score for Canadians had not changed significantly since the 1994 survey. However, there was a noticeable positive change in average scores among the $5 \%$ of Canadians with the lowest literacy scores. The survey also found a slight decline in the inequality gap between adults with the lowest and those with the highest literacy scores. Nevertheless, about $42 \%$ of Canadians from age 16 to 65 had skills in the lowest 2 levels on the prose scale. This shows that they would have some difficulty meeting everyday reading 
requirements. Fifteen percent scored in the lowest level - down slightly from $17 \%$ in 1994. According to the initial report by Statistics Canada, this means that well over 3 million Canadians aged 16 to 65 have problems dealing with printed materials. This suggests that literacy is still a very significant problem in Canada.

With regard to its relationship to health, there is evidence that literacy is directly related to overall health status and mental health status. ${ }^{10-13}$ For example, consumers with low levels of literacy and their families appear to be at risk of harm due to their difficulty reading medication prescriptions, baby formula instructions, and other written material. ${ }^{4}$

There is also evidence that literacy has indirect links to health. For example, people with low literacy skills appear to be more likely to have lower incomes ${ }^{14}$ and to be unemployed and working for minimum wage in unskilled jobs. ${ }^{15}$ They tend to be less aware of and make less use of preventive services: ${ }^{16}$ they are less likely to seek care, ${ }^{11}$ have higher rates of hospitalization, ${ }^{17}$ and experience more difficulties using the health care system. ${ }^{18,19}$

In addition, people with limited literacy also have less knowledge about medical conditions and treatment. ${ }^{20}$ They have trouble understanding health issues generally. ${ }^{21}$ They also have more difficulty understanding and communicating with practitioners. ${ }^{8}$ This suggests that low "general literacy" is related to low "health literacy." Health literacy has been defined as: "The degree to which individuals have the capacity to obtain, process and understand basic health information and services needed to make appropriate health decisions." ${ }^{22}$ This commonly used definition was accepted by the Institute of Medicine Committee. The committee also stressed the importance of multiple health-related contexts such as home, work, community, and care institutions in defining health literacy.

The capacities or abilities that comprise health literacy have been found to be related to health outcomes. For example, a recent study of breast cancer patients found that patients who reported difficulty in accessing health information experienced lower emotional, functional, and social or family well-being. ${ }^{23}$ Similarly, a recent study of war veterans with diabetes found that understanding self-care behav- iours was strongly and independently associated with self-management of their condition. ${ }^{14}$ Unfortunately, the most commonly used measures of health literacy do not measure the capacities in the definition. This suggests the need for new measures to be developed that focus on both the person and the context.

Finally, as suggested from the findings on income, it has also been noted that literacy is related to the broader determinants of health. For example, there is a strong relationship between education and literacy levels. ${ }^{12}$ However, education and literacy are not perfectly correlated, and literacy itself is a strong predictor of health. ${ }^{12}$ This suggests that perhaps "literacy" is a "mechanism" through which education has an impact on health. In other words, literacy is an important outcome of the education process, which has both a direct and indirect impact on the health of individuals and populations.

Thus, although our knowledge is not perfect, there is evidence, based on research, suggesting that a concern about the effect of literacy on health is justified and that we need to increase our efforts to address the problem though programs, policies, and further research. The intent of the Second Canadian Conference on Literacy and Health was to contribute to this process. One of the questions that this journal supplement attempts to answer is: to what extent did the conference do so?

\section{Overview of the Journal Supplement}

As noted, authors were asked to address three questions: 1) What did we learn from the conference? 2) What didn't we learn? and 3) What should we do now? The questions are related to the four themes: 1) Building Best Practices; 2) Focusing on Language and Culture; 3) Building Knowledge; and 4) Building Healthy Public Policy. The second theme was also addressed in relation to three perspectives (Francophone, Aboriginal, and ethnocultural). There is also a concluding article. Thus, the seven articles that follow are:

- Critical Analysis on Best Practices in Health Literacy by Linda Shohet and Lise Renaud

- Social Capital, Health and Francophone Minorities by Louise Bouchard, Anne Gilbert, Rodrigue Landry, and Kenneth Deveau
- Culture-based Literacy and Aboriginal Health by Janet Smylie, Lewis Williams, and Nancy Cooper

- Health Literacy Within the Reality of Immigrants' Culture and Language by Margareth Zanchetta and Iraj Poureslami

- Building Knowledge in Literacy and Health by Heather Hemming and Lisa Langille

- Building Healthy Public Policy by Lynn Chiarelli and Peggy Edwards

- As the Ship Sails Forth by Irving Rootman and Peggy Edwards

We encourage you to read these articles to learn what "The Captain's Log" has to say that is relevant to your work or interests. Let us know what you think by contacting us at: literacyandhealth_conf@cpha.ca.

\section{REFERENCES}

1. Canadian Public Health Association. The Captain's Log: Charting the Course for Literacy and Health in the New Millennium. Ottawa, ON: Canadian Public Health Association, 2001.

2. Rootman I, Quantz D. Canadian Graduate Student Workshop on Literacy and Health Research, 2004. Available online at: http://www.nlhp.cpha.ca/clhrp/index_e.htm (Accessed March 30, 2006).

3. Calamai P. Broken Words: Why Five Million Canadians Are Illiterate: A Special Southam Survey, 1987.

4. Statistics Canada. Reading the Future: A Portrait of Literacy in Canada, 1996. Available online at: http://www.statcan.ca/bsolc/english/bsolc?catno= 89-551-X (Accessed March 30, 2006).

5. Ontario Public Health Association and Frontier College. Literacy and Health Project Phase One: Making the World Healthier and Safer for People Who Can't Read, 1989. Available online at: http://www.opha.on.ca/resources/literacylsummary.pdf (Accessed March 30, 2006).

6. Breen MJ. Partners in Practice: Literacy and Health Project, Phase Two. Toronto, ON: Ontario Public Health Association and Frontier College, 1993.

7. Federal, Provincial and Territorial Advisory Committee on Population Health, Toward a Healthy Future: Second Report on the Health of Canadians. Ottawa: Health Canada, 2000.

8. Neilsen-Bohlman L, Panzer AM, Kindig DA (Eds.). Health Literacy: A Prescription to End Confusion. Washington, DC: The National Academies Press, 2004.

9. Based on data in Statistics Canada. Adult Literacy and Life Skills Survey. The Daily, 2005. Available online at: http://www.statcan.ca/Daily/English/ 050511/d050511b.htm (Accessed March 30, 2006).

10. Baker DW, Parker RM, Williams MV, Clark WS, Nurss J. The relationship of patient reading ability to self-reported health and use of health services. Am J Public Health 1997;87(6):1027-30.

11. Baker DW, Gazmararian JA, Williams MV, Scott T, Parker RM, Green D, et al. Functional health literacy and the risk of hospital admission among Medicare managed care enrollees. Am J Public Health 2002;92(8):1278-83.

12. Roberts P, Fawcett G. At Risk: A Socio-economic Analysis of Health and Literacy Among Seniors. 
Statistics Canada, 1998. Cat. No. 89-552-MPE, no. 5 .

13. Kalichman SC, Ramachandran B, Catz S. Adherence to combination antiretroviral therapies in HIV patients of low literacy. J Gen Intern Med 1999;5:267-73.

14. OECD and Statistics Canada. Literacy, Economy and Society: Results of the First International Literacy Survey. Statistics Canada Catalogue No. 89-545E. Ottawa: OECD Paris and Minister of Industry, 1995.

15. Scott TL, Gazmararian JA, Williams MV, Baker DW. Health literacy and preventive health care use among Medicare enrollees in a managed care organization. Medical Care 2002;40(5):395-404.

16. Bennett CL, Ferreira MR, Davis TC, Kaplan J, Weinberger M, Kuzel T, et al. Relation between literacy, race, and stage of presentation among low-income patients with prostate cancer. J Clin Oncol 1998;16(9):3101-4.

17. Davis TC, Meldrum H, Tippy PKP, Weiss BED, Williams MV. How poor literacy leads to poor health care. Patient Care 1996;30:94-127.

18. Brez SM, Taylor M. Assessing literacy for patient teaching: Perspectives of adults with low literacy skills. J Adv Nurs 1997;25:1040-47.

19. Parker RM, Ratzan SC, Lurie N. Health literacy: A policy challenge for advancing high quality health care. Health Affairs 2003;22(4):147.

20. Rudd RE, Moeykens BA, Colton T. Health and literacy: A review of medical and public health literature, NCSALL: The Annual Review of Adult Learning and Literacy, Volume 1: Chapter Five, 1999.
21. Schillinger D, Grumbach K, Piette J, Wang F, Osmond D, Daher C, et al. Association of health literacy with diabetes outcomes. JAMA 2002;288(4):475-82.

22. Arora NK, Johnson P, Gustafson DH, McTavish F, Hawkins R, Pingree S. Barriers to information access, perceived health competence, and psychosocial health outcomes: Test of a mediation model in a breast cancer sample. Patient Education and Counseling 2002;47:37-46.

23. Heisler M, Bouknight RR, Hayward RA, Smith DM, Kerr EA. The relative importance of physician communication, participatory decisionmaking, and patient understanding in diabetes selfmanagement. J Gen Intern Med 2002;17:243-52. 